\title{
Massive Pleural Effusion as a Rare Manifestation in Severe Neonatal Sepsis
}

\author{
Adriana Lukmasari ${ }^{1,2} \mathbb{D}$, Jeffry Trialimas ${ }^{2}$, Wim Khairu Taqwim ${ }^{3}$, Cipta Pramana ${ }^{4,5 *}$ (D) \\ ${ }^{1}$ Department of Pediatrics, KRMT Wongsonegoro Hospital, Semarang, Indonesia; ${ }^{2}$ Department of Pediatrics, Medical Faculty, \\ Tarumanagara University, Jakarta, Indonesia; ${ }^{3}$ Department of Surgery, KRMT Wongsonegoro Hospital, Semarang, Indonesia; \\ ${ }^{4}$ Department of Obstetrics and Gynecology, KRMT Wongsonegoro Hospital, Semarang, Indonesia; ${ }^{5}$ Department of Obstetrics \\ and Gynecology, Medical Faculty, Tarumanagara University, Jakarta, Indonesia
}

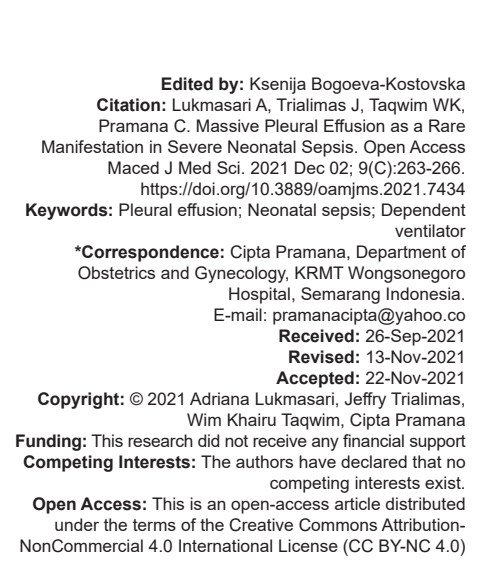

Abstract

BACKGROUND: Neonatal sepsis can be severe and has mortality rate. The pleural effusion is a rare sign of severe sepsis in newborn and only few studies that reported it.

CASE PRESENTATION: We report a case of newborn who referred to our hospital because of dependent mechanical ventilator and severe sepsis. We found a massive pleural effusion and did the pleural drainage. After the drainage, the baby was extubate and discharge well with no signs of respiratory distress.

CONCLUSION: Massive pleural effusion might be considered as a cause of dependent ventilator in severe neonatal sepsis.

\section{Introduction}

Neonatal sepsis is a diagnosis made in infants $<28$ days of life. Neonatal sepsis maybe divided into two types: Early onset neonatal sepsis and late onset neonatal sepsis [1]. The early onset of neonatal sepsis occurs within 7 days of life after birth while the late onset occurs more than 7 days after birth. Fleischmann et al. reported that the incidence of neonatal sepsis was 2824 sepsis cases per 100.000 live births [2]. Estimated incidence and mortality were higher in early onset than late onset neonatal sepsis cases. In Indonesia, infant mortality rate is $19 / 1000$ live births or around 236 /days and ten people per hour. Sepsis becomes the biggest cause with presentation of $20.6 \%$ from age 0 to 28 days and around $12 \%$ of age $0-6$ days [3].

Neonatal sepsis is one of the major causes of morbidity and mortality in newborn. Early onset neonatal sepsis is a severe disease and has high mortality rate.

Several factors of mother, babies, and environment are contributed to the infection exposed and non-optimal of immunologic response so as the newborn become susceptible to be infection. Clinical manifestation of neonatal sepsis is varied from non-specific such as feeding intolerant until the worst or severe manifestations such as apnea [1], [4].

Pleural effusion is rare clinical manifestation in neonatal sepsis [5]. There are two types of pleural effusion such as non-chylous and chylous. The previous case report from Chandran et al. reported congenital pleural effusion in neonate [6]. Chylous effusion is milky-white after milk feeds or hemoserous in color with an absolute cell count of greater than $1000 / \mathrm{mm}^{3}$, lymphocyte fraction greater than $80 \%$, and triglyceride level $>1.1 \mathrm{mmol} / \mathrm{l}$. Non-chylous effusion could be a transudate or exudate. Transudates have total protein $<30 \mathrm{~g} / \mathrm{L}$ and white blood cell (WBC) fewer than $2000 / \mathrm{mm}^{3}$ with a predominance of mononuclear cells whereas exudates have high protein levels and predominance of polymorphonuclear cells. Exudative fluid may show the pathogen in gram stain or culture [6], [7]. Massive pleural effusion can lead to respiratory distress in infants, and it is still a very rare disease that we must pay attention to. Only a few studies reported the incidence of massive pleural effusion in severe neonatal sepsis. Hence, in this article, we try to explain the successful management of massive pleural effusion in a 3-week-old baby who suffered from severe sepsis. 


\section{Case Report}

A term female baby was born by spontaneous vaginal delivery technique by midwife, with a birth weight of $3800 \mathrm{~g}$ from a gravida three mother. The baby was not vigorous at birth and delivered to the region hospital at sub urban city. The APGAR score was six on $1 \mathrm{~min}$ and the mother had a premature rupture of membrane for approximately 2 days. She was hospitalized with nasal continuous positive airway pressure for a week. After that, the condition was stable and she was discharged home. Two days at home she got fast breathing and high fever, so she hospitalized again in the same hospital. She required endotracheal intubation and started a mechanical ventilator for almost 3 weeks. She was depended on mechanical ventilator and the symptoms became worsening, so she referred to our hospital at KRMT Wongsonegoro hospital in Semarang, Indonesia.

On physical examination, the baby was weak and somnolent; vital signs were as follows: Pulse $180 \times / \mathrm{min}$, respiratory rate $(\mathrm{RR})$ controlled by positive ventilation, temperature $36.3^{\circ} \mathrm{C}, 92 \%$ oxygen saturation, mottled skin, and vesicular breath sound was found more weaker on the right thoracic auscultation, with rhonchi on both lung, and wheezing was absent.

The patient was then transferred to the neonatal intensive care unit (NICU), and the ventilator setting was $80 \% \mathrm{FiO}_{2}, \mathrm{PEEP} 6 \mathrm{cmH}_{2} \mathrm{O}, \mathrm{PC} \mathrm{12}$, and RR 40. Moreover, a babygram (Figure 1) was performed after and showed that the baby had a shallow ETT, neonatal pneumonia, and massive pleural effusion on the right lung. The laboratory examination revealed hemoglobin level $11.7 \mathrm{~g} / \mathrm{dL}$, hematocrit 36\%, leukocytes 22.3/uL, thrombocytes $337 / \mathrm{uL}$, ureum $20.2 \mathrm{mg} / \mathrm{dL}$, creatinin 1.43 $\mathrm{mmol} / \mathrm{L}$, albumin $3 \mathrm{~g} / \mathrm{dL}$, calsium $1.43 \mathrm{mmol} / \mathrm{L}$, kalium $6.50 \mathrm{mmol} / \mathrm{L}$, natrium $136 \mathrm{mmol} / \mathrm{L}$, CRP 152, and blood glucose $80 \mathrm{mg} / \mathrm{dL}$. Patient received fluid resuscitation, dobutamin $3 \mathrm{meq} / \mathrm{kgbw} /$ day, methylprednisolone $5 \mathrm{mg} / 8 \mathrm{~h}$, calcium gluconate $2 \mathrm{cc} / 12-\mathrm{h}$, meropenem $100 \mathrm{mg} / 12-\mathrm{h}$, amikacin $40 \mathrm{mg} / 24 \mathrm{~h}$, and maintenance fluid of $10 \%$ dextrose.

On the following day, a thoracocentesis followed by pleural drainage procedure was performed by general surgeon using $4 \mathrm{Fr}$ size of pigtail catheter. Initially, $40 \mathrm{cc}$ of fluid was aspirate and would be continued every day. Specimen samples were obtained from pleural fluid, ETT, and blood was sent for anatomy pathologic and microbiology study. Acinetobacter baumanii was obtained on culture of ETT sample, cytology study of pleural fluid shown a non-specific inflammation. We found no bacterial in blood culture.

On the $4^{\text {th }}$ day, a total of $130 \mathrm{cc}$ effusion fluid was drained. Weaning of mechanical ventilation was carried out at the $5^{\text {th }}$ day and the symptoms of patient had improved. Patient was extubated at the $6^{\text {th }}$ day and oxygen therapy was also changed to nasal cannula.

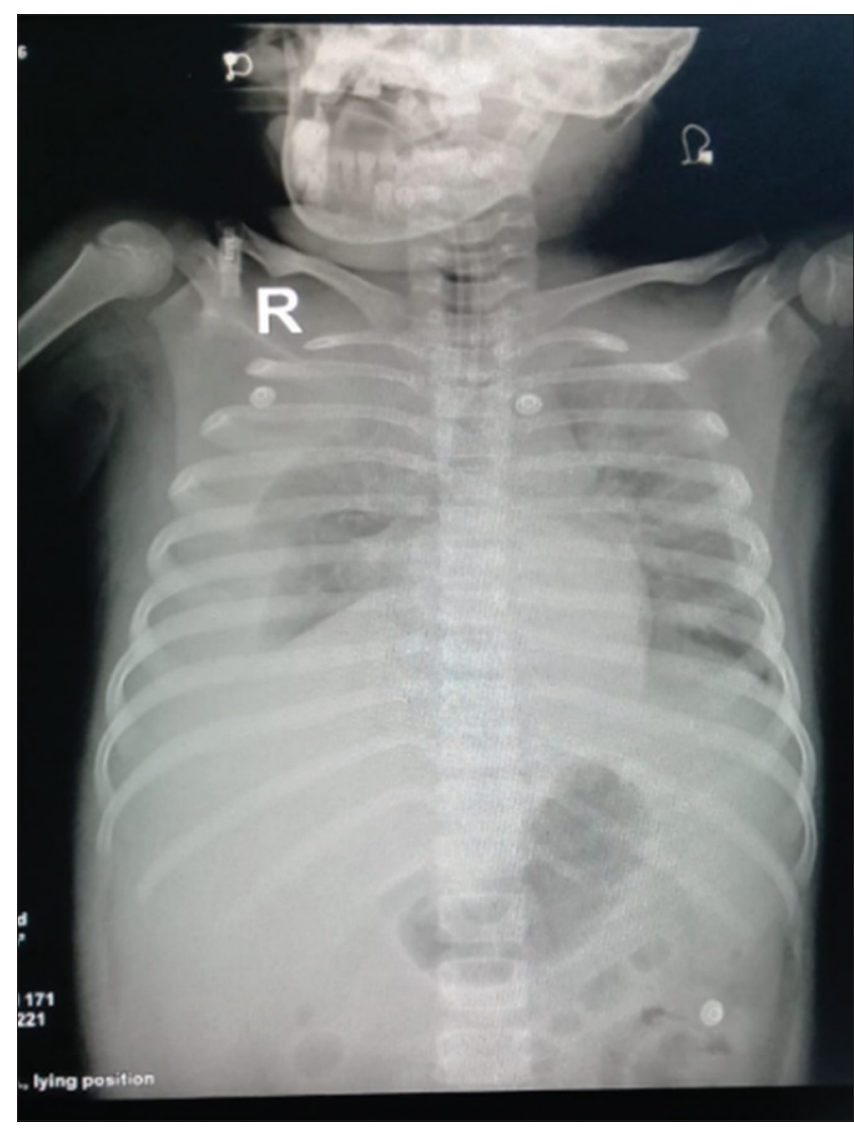

Figure 1: X-ray showing a massive right pleural effusion

Chest drain was taking out on the next day. A babygram (Figure 2) obtained after chest drain removal shown no sign of pleural effusion. The evaluation of laboratory examination was done with the following result: SGPT: 76 U/L; SGOT: $92 \mathrm{U} / \mathrm{L}$; indirect bilirubin: $0.56 \mathrm{mg} / \mathrm{dL}$; CRP: $3.30 \mathrm{mg} / \mathrm{L}$; direct bilirubin: $0.34 \mathrm{mg} / \mathrm{dL}$; hemoglobin: $12.6 \mathrm{~g} / \mathrm{dL}$; hematocrit: $36.10 \%$; thrombocites: $589 / \mathrm{uL}$; bilirubin total: $0.90 \mathrm{mg} / \mathrm{dL}$; and leukocyte: $10.7 / \mathrm{uL}$. The baby showed no sign of respiratory distress, well breast fed, and discharged home.

\section{Discussion}

Hematyar et al. proved that the most common clinical manifestations were respiratory distress in $49(44.5 \%)$, jaundice in $28(25.5 \%)$, vomiting in $26(23.6 \%)$, and poor feeding in $23(20.9 \%)$ of the infants. Other clinical manifestations were lethargy (weakness), decreased sucking reflex, fever, tremor, abdominal distention, and seizure, found in $12(10.9 \%), 10(9.1 \%)$, $4(3.6 \%),(3.6 \%), 3(2.7 \%)$, and $2(1.8 \%)$ neonates. In fact, respiratory distress was more common in early onset sepsis while jaundice, fever, and seizure were associated with late onset sepsis [8].

Many studies have been conducted on the diagnosis of neonatal sepsis, such as complete blood 


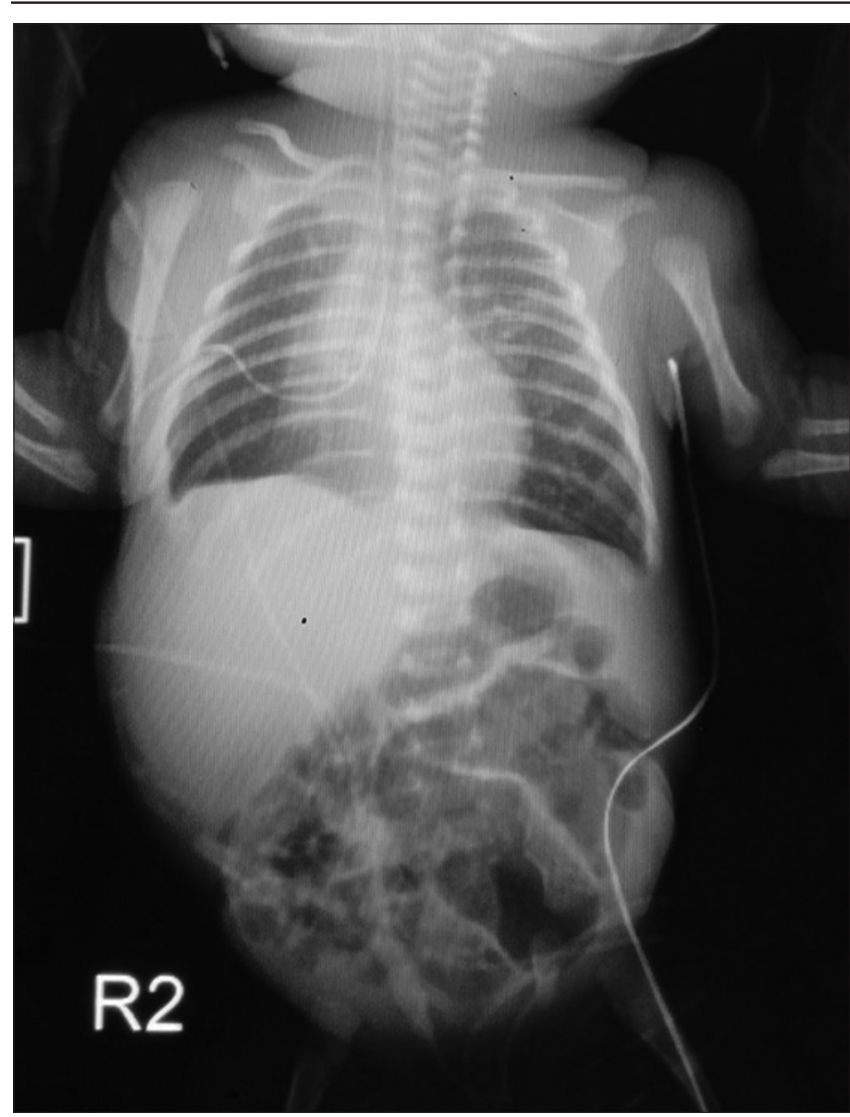

Figure 2: X-ray on $6^{\text {th }}$ day showing normal lung fields

count, WBC count, absolute neutrophil count, and the ratio of immature neutrophil count to total neutrophil count $(I / T)$. The WBC upper limit is set at 30.000-40.000/ $\mathrm{mm}^{3}$ in many sepsis screening protocols. However, it is noteworthy that leukocytosis was not detected in onethird of cases diagnosed with sepsis. CRP, which is a pentameric structure, containing 187 amino acids and synthesized from hepatocytes, and an acute-phase protein, is one of the most easily available and most frequently used laboratory tests in the diagnosis of neonatal sepsis. Serial CRP measurements are also used to evaluate the antibiotic response [8], [9].

The gold standard for the diagnosis of neonatal sepsis is the growth of pathogenic microorganisms in body fluids (blood, urine, cerebrospinal fluid, pleural fluid, peritoneal fluid, and joint fluid) [9]. While the growth of the microorganism in blood culture is diagnostic in the neonatal period, the failure to produce it does not exclude the diagnosis. No growth in culture may be related to insufficient sample, mother's antibiotic use, antibiotic dose applied before sampling, low amount of bacteria in the blood, or short-term bacteremia [10]. The using of EMA scoring system to diagnose is very easy to be applied [11]. It combines between clinical manifestation and laboratory examination.

We found several clinical manifestations in our case such as fever, respiratory distress, tachycardia, and mottled skin. Our laboratory also revealed high CRP. It fulfilled the EMA scoring system. We also had endotracheal secret specimen and the result was
Acinetobacter baumanii. We had negative result for blood culture supposing that patient already treated by several antibiotics regimen before.

Murthy et al. proved that risk factor becoming neonatal sepsis is male sex (OR: $1.3,95 \% \mathrm{Cl}: 1.02,1.68)$, out born neonates (OR: $5.5,95 \% \mathrm{Cl}: 2.39,12.49)$, need for artificial ventilation (OR:5.61;95\% Cl:8.21, 41.18), gestationalage <37 weeks (OR:2.05; $95 \% \mathrm{Cl}: 1.40,2.99$ ), and premature rupture of membranes (OR: 11.14, 95\% Cl: 5.54, 22.38) [12]. In our case, we found that the baby was not delivered at hospital, had a low apgar score, and got a mechanical ventilator. Furthermore, there was a risk form her mother premature rupture of membrane.

Management of neonatal sepsis is aimed at treating the underlying infectious cause of sepsis and correcting the associated organic dysfunction through, for example, respiratory support, circulatory support, and correction of metabolic, temperature and glucose derangements. Preliminary results have shown that early initiation of antibiotic therapy in neonates with suspected sepsis seems to reduce both mortality and morbidity. The antibiotic therapy is empirical and based on several factors such as age at onset, likely pathogens, and antibiotic susceptibility patterns [13]. Pokhrel et al. reported that 336 neonates admitted in the NICU, 69 (20.5\%) had culture-positive sepsis. The majority were early onset sepsis ( $n=54,78.3 \%$ ) and were among the preterm babies ( $n=47,68.1 \%)$. The most bacterial isolates were Gram-negative, predominantly the Klebsiella species ( $n=23,33.3 \%$ ). Klebsiella showed the high resistance to commonly used antibiotics such as; cefotaxime (90.5\%), gentamicin (75\%), ciprofloxacin $(76.2 \%)$, ofloxacin $(72.2 \%)$, and chloramphenicol (65\%). However, they showed good susceptibility to carbapenems (100\%), colistin $(88.8 \%)$, and tigecycline (81.8\%) [14]. In our case, we considered the use of carbapenem regiment because the patient had long hospitalizations before she referred to our place. The blood culture showed Acinetobacter baumaii which is sensitive to carbapenem therapy.

Accumulation of fluid in pleural space of lungs is termed pleural effusion. Causes of such occurrence in newborn include congenital, non-immune, and immune hydrops, secondary to leaky capillaries, iatrogenic injury to thoracic duct leading to collection of chyle, Down and Turner syndromes, pneumonia, and wet lung syndrome [15]. Pneumonia can complicate with the spreading of bacterial infection within the thoracic cavity, resulting in pleural effusions, usually empyemas. Staphylococcus aureus, Streptococcus pneumoniae, and Streptococcus pyogenes are the most common causes; other agents include Bacteroides fragilis, Acinetobacter calcoaceticus, Acinetobacter spp., and Enterobacter aerogenes [16]. There were also differences on treatment modalities between types although thoracocentesis was equally performed; chest tube drainage was particularly used in chylothoraces 
while diuretic therapy was a frequent option for transudates [15], [16]. These are consistent with our case that the baby has exudate form of pleural effusion due to neonatal pneumonia and sepsis. The pathogen bacteria were Acinetobacter sp. Our limitation is we did not examine the composition of effusion such as protein, cell, and glucose level. We also did the chest tube drainage for several days.

\section{Conclusion}

The pleural effusion is a rare manifestation of severe sepsis and has atypical presentation in neonate. We suggest the clinician considering pleural effusion in neonate that has respiratory distress especially difficult for weaning mechanical ventilator.

\section{Acknowledgment}

Thank you to the patient's parents for agreeing to have their case published.

\section{References}

1. Ershad M, Mostafa A, Dela Cruz M, Vearrier D. Neonatal sepsis. Curr Emerg Hosp Med Rep. 2019;7(3):83-90. https:// doi.org/10.1007/s40138-019-00188-z

PMid:32226657

2. Fleischmann C, Reichert F, Cassini A, Horner R, Harder T, Markwart R, et al. Global incidence and mortality of neonatal sepsis: A systematic review and meta-analysis. Arch Dis Child. 2021;106(8):745-52. https://doi.org/10.1136/ archdischild-2020-320217

\section{PMid:33483376}

3. Hayun M, Alasiry E, Daud D, Febriani DB, Madjid D. The risk factors of early onset neonatal sepsis. Am J Clin Exp Immunol. 2015;3(3):78
4. Iroh Tam PY, Bendel CM. Diagnostics for neonatal sepsis: Current approaches and future directions. Pediatr Res. 2017;82(4):574-83. https://doi.org/10.1038/pr.2017.134 PMid:28574980

5. Sadeghi-Moghadam P, Pourazizi M, Shafieyoon S. Nonchylous bilateral pleural effusion in a newborn: A rare case. J Res Med Sci. 2019;24:11. https://doi.org/10.4103/jrms.jrms_799_18 PMid:30988679

6. Chandran S, Emilia K, Chong CF. Isolated non-chylous congenital pleural effusion in a neonate-case report and review of literature on current prenatal and postnatal mangement. Brunei J Health. 2009;4:18-21.

7. Wood RE. Diagnostic procedures. In: Nelson Textbook of Paediatrics. W. B. Philadelphia, PA, United States: Saunders; 1996. p. 1183.

8. Hematyar M, Najibpour R, Bayesh S, Hojjat A, Farshad A. Assessing the role of clinical manifestations and laboratory findings in neonatal sepsis. Arch Pediatr Infect Dis. 2017;5(1):e29985.

9. Odabasi IO, Bulbul A. Neonatal sepsis. Sisli Etfal Hastan Tip Bul. 2020;54(2):142-58. https://doi.org/10.14744/SEMB.2020.00236 PMid:32617051

10. Gerdes JS. Diagnosis and management of bacterial infections in the neonate. Pediatr Clin North Am. 2004;51:939-59. https:// doi.org/10.1016/j.pcl.2004.03.009

PMid:15275982

11. European Medicines Agencies (EMA). Report on the Expert Meeting on Neonate and Paediatric Sepsis. London: European Medicines Agencies; 2010.

12. Murthy S, Godinho MA, Guddattu V, Lewis LE, Nair NS. Risk factors of neonatal sepsis in India: A systematic review and meta-analysis. PLoS One. 2019;14(4):e0215683. https://doi. org/10.1371/journal.pone.0215683 PMid:31022223

13. Korang SK, Safi S, Gluud C, Lausten-Thomsen U, Jakobsen JC Antibiotic regimens for neonatal sepsis-a protocol for a systematic review with meta-analysis. Syst Rev. 2019;8(1):306. https://doi.org/10.1186/s13643-019-1207-1 PMid:31805993

14. Pokhrel B, Koirala T, Shah G, Joshi S, Baral P. Bacteriological profile and antibiotic susceptibility of neonatal sepsis in neonatal intensive care unit of a tertiary hospital in Nepal. BMC Pediatr. 2018;18(1):208. https://doi.org/10.1186/s12887-018-1176-x PMid:29950162

15. Khemani S, Mirza A, Irfan O, Qamar MA, Mumtaz M, Ali SB, et al. Successful resolution of congenital idiopathic non-chylous pleural effusion in newborn. Integr Pediatr. 2021;2(1):106.

16. Barbosa M, Rocha G, Flôr-de-Lima F, Guimarães H. Neonatal pleural effusions in a level III neonatal intensive care unit. J Pediatr Neonatal Individ Med. 2015;4(1):e040123. 